\title{
Needs of Families in Perinatal Palliative Care and Proposal for a Model Training Questionnaire
}

\author{
Rita Rufo ${ }^{\star}$ Adriana Boccarato, and Magdalena Lujambio \\ Department of Neonatology, Pereira Rossell Hospital, Montevideo, Uruguay
}

*Corresponding author: Rita Rufo, Department of Neonatology, Pereira Rossell Hospital, Montevideo, Uruguay, E-mail: rrufo@mednet.org.uy

Citation: Rita Rufo, Adriana Boccarato, Magdalena Lujambio (2017) Needs of Families in Perinatal Palliative Care and Proposal for a Model Training Questionnaire. J Anesth Pati Care 2(1): 104. doi: 10.15744/2456-5490.2.104

Received Date: October 07, 2017 Accepted Date: December 13, 2017 Published Date: December 13, 2017

\begin{abstract}
In accordance with WHO palliative care principles, Perinatal Palliative Care is a biopsychosocial and spiritual approach to sustain and improve the patients and families' life quality facing the problems associated with limiting and / or life-threatening diseases that start in the context of perinatality, in a broad sense, even when the disease and / or death occur later. We understand by family the unit to treat. The objectives of this work are: a) to describe the needs (physical, emotional, behavioral, spiritual and social) and coping resources of the families assisted during hospitalization within a period of five years; b) to develop a model questionnaire for training in the recognition of those needs. It is a descriptive, observational and retrospective study. Results: 379 families were included in the analyzed period and the observations, expressed in relative frequency. The importance of attending to families' physical needs is emphasized ; differences of expression between man (manifestation of anger) and woman (feeling of guilt) are found, and important resources are recognized as useful to reinforce coping with the situation ; for instance, providing families with support, creating social programs, favoring integration with other families in similar situations. Conclusions: Further studies are required in order to generalize the results and the proposed questionnaire will be subject to modifications during validation. However, this study allowed the authors to propose and implement improvements in the care of families. A questionnaire proposed for recognition of these topics could be useful to choose strategies for approaching perinatal palliative care.
\end{abstract}

Keywords: Perinatal palliative care; Family’s health; Perinatal palliative training

\section{Introduction}

In accordance with WHO principles [1] of palliative care we adapted the definition as a "bio-psycho-social and spiritual approach to sustain and improve patients' and families' life quality facing the problems associated with limiting and /or life threatening diseases that begin in the context of perinatal stage in a broad sense, even when the disease and / or death occur later". [2] In a broad sense means that, even though WHO defines perinatal period as from 22 weeks to 7 days postnatal, technologic advances imply changes in the duration of that period.

The unit to treat is the family. There are many definitions around what is considered to be a family. WHO definition of family is: "members of the family related to one another, to a degree determined by blood, adoption and marriage." [3] Definition by Family Medicine: "The family is a social group, organized as an open system, constituted by a variable number of members, which in most cases coexist in the same place, linked by consanguineous, legal and / or affinity bonds." [4] We prefer to consider Áres Muzio's definition:"Union of people who share a vital project of existence in common, which is long lasting, which generates strong feelings of belonging to this group; there is a personal commitment among its members and intense relationships of intimacy, reciprocity and dependence are established." [5]

WHO defines: "Family health is evaluated from its capacity to fulfill its functions, adapt and overcome the crises with its own resources." [6] Zeidner and Hammer (1992) define follow -up resources as: "all those personal and social variables that allow people to handle stressful situations more efficiently." [7] MASLOW (1943) observed that: "basic needs have to be covered for higher needs to appear. It is understood by NEED all that is indispensable to live in a state of full health." [8] We have to identify the families' needs and coping resources to provide quality care. We believe that teaching to identify them early is crucial. "Illness, disability and death are universal experiences that make families face one of the greatest challenges of life". [9] Palliative care is inherent to the human being's dignity at any stage of life. The perinatal period still offers high morbidity and mortality, requires highly specialized care as 
well as quality palliative care. The early approach, since the diagnosis, allows the possibility to create a close link to help families find a new comfort zone. The decision making at the end of life is a complex process that requires our training and ethics. Prenatal palliative care is a holistic approach of the fetus and its family from the diagnosis of the disease or condition that limits or threatens its life,which follows the decision-making process and prepares parents and team for the different possible scenarios at birth and postnatal, including support during mourning. The purpose of the present study is to provide greater knowledge about families' needs and coping resources in perinatal palliative care to achieve a better approach and training.

\section{Material and method}

\section{Study method}

This is a qualitative approach with a retrospective, observational and descriptive study.

Inclusion criteria: The families that required Perinatal Palliative Care in a state maternity of Montevideo, the capital of Uruguay, in a period of five years (2010-2015) who had no less than three interviews during hospitalization are included.

\section{Material}

The observation is based on a review of records of the interviews made to each family. Those families are usually referred to us by obstetricians, neonatologists, sonographers, geneticists or as part of previously agreed protocol. The author meets each family at least three times during hospitalization. The interviews are coordinated personally or by telephone (available 24 hours a day). These interviews are conducted in an interview room to avoid interference. When they have a prenatal diagnosis they usually have more than one hospitalization done prenatally and many interviews are in the hospital room or in a birth room (especially in case of end of life). During the post natal period families sometimes prefer to stay with the baby and some interviews take place in the neonatal hospitalization area that corresponds.

The observations are translated into a database. We extracted the questions from the real interviews to propose a questionnaire based on the most frequent observations. The first author of this study has participated in more than ninety percent of the interviews conducted during the analyzed period and from which the questions are taken.

\section{Variables analyzed}

The variables to describe families' needs and coping resources, observed during hospitalization, are extracted from the analysis of each report and classified as:

NEEDS (difficulties that require attention):

1. Physical: basic needs and physical symptoms.

2. Emotional: expression of emotions that disturb families' well-being.

3. Behavioral: actions or reactions in response to the situation.

4. Spiritual: expression of existential beliefs and values related to meaning and purpose.

5. Social: demand of social benefits or programs.

COPING RESOURCES (Own response to the situation).

6. a) Positive or b) negative

Factors that facilitate or make it more difficult to tolerate the stressful situation.

\section{Ethical questions}

No identifying information is attached. The authors have no conflict of interest

\section{Results and Discussion}

A bibliographic search was carried out by Pub Med finding 2265 articles for the needs of families in palliative care, 237 pediatric ones, 76 neonatal ones, 24 perinatal ones but 0 training questionnaires. We have not found a study of similar characteristics to this one in the bibliography consulted.

The results are grouped according to: 1) description of needs classified as physical, emotional, behavioral, spiritual and social; 2) description of coping resources to the crisis or bereavement classified as positive and negative; and 3) based on these results, a training questionnaire for health personnel is proposed.

Results are expressed as relative frequency ( $\mathrm{Fr}=\mathrm{n}$ observed families / $\mathrm{N}$ total families included) Observations with a relative frequency of 0.3 to 0,49 are identified and those with a relative frequency of 0.5 or higher are distinguished with underlined words.

\section{Families included}

Three hundred seventy nine (379) families are included in the period of five years in a public hospital with about seven thousand (7.000) births per year. In general users belong to middle or low social classes. $40 \%$ of the families included are referred to the maternity from rural areas and $60 \%$. From the capital, Montevideo. Typically, we recognized three groups of diseases which predominate: malformations and chromosomopathies (48\%); extreme preterm (29\%) and hypoxic - ischemic syndrome (8\%) and others (as infections, intrauterine growth restriction and others). The first group was the one with the highest prenatal intake. [7] 
Perinatal palliative care has been integrated since 2010 in an open model. We think like other authors that:

"The neonatal intensive care unit needs a mixed model of palliative care, where the neonatal team provides primary palliative care and the palliative subspecialist consults for more complex or refractory situations that exceed the primary team's skills or available time." [10]

"Regarding the intervention criteria of the specific teams, a model based mainly on the prognosis of weeks and on the intervention of a dissociated and rigid character, has evolved towards another model based on the needs and complexity of patients and families. This latter model is characterized by being flexible and cooperative, with shared interventions, in which the longer prognosis of life or the indications of specific treatment are not barriers to intervention". [11]

\section{Description of needs results}

Physical needs: At least a third of the population presented at some point increase demand for the satisfaction of physical needs. The presence of pain or the incapacity to eat or rest is common and linked to the emotional impact of the situation. Symptoms' from previous conditions may appear as well. This problem becomes more evident in men or when families come from the countryside. As Maslow [12] describes: it is observed that physical needs are basic and need to be satisfied for people to be able to overcome other needs.

Emotional needs: Some differences between men's and women's emotional needs have been noticed. Guilt is the main emotional need observed, especially in women.

Women: Feelings of guilt (Fr 0, 9), anguish, emotional instability, fear that their pain or crying generates more suffering to the patient, anguish for not being able to explain to their other children what happens, self-esteem disorder (especially in case of intrauterine death).

Men: Increased anger and difficulty in expressing feelings. They want to be strong for their family.

Behavioral needs: Initial confusion lasts longer in women and when there is no prenatal diagnosis. In this situation they have more difficulty taking decisions. Competence for baby care generates conflict during nursing. There is a biphasic demand: they claim attention in the critical period and then prior to their discharge to home. They have difficulty verbalizing medical reports to others and difficulties in family relationships arise. Exclusion of other members (especially siblings) is observed. Differences with their partner: their different way of expressing suffering generates anger.

A report (2008) of a systematic literature review of research on parent participation in the care of hospitalized children confirmed parents' desire and expectations to participate in their child's care. [13]

Spiritual needs: Some spiritual needs observed are: questioning beliefs or desire to "leave it in God's hands", expression of the desire to fulfill motherhood, search for meaning. Even if they do not have a religion they need to make sense of what is happening to them.

"Barriers to these programs include lack of services, difficulty identifying the dying point, discomfort in withholding or withdrawing treatments, communication problems, conflicts in care among providers and between parents and providers, and differences in cultural beliefs about end-of-life care. The 2011 NIH Summit on the Science of Compassion provided recommendations in family involvement, end-of-life care, communication, health care delivery, and transdisciplinary participation." [14]

Social needs: Lack of knowledge or misuse of benefits, are greater in dysfunctional families or among people coming from the countryside.

\begin{tabular}{|c|c|c|c|}
\hline N 379 & \multicolumn{3}{|c|}{$\begin{array}{l}\text { Families Results expressed as relative frequency }(\mathrm{Fr}=\mathrm{n} \text { observed families / } \mathrm{N} \text { total families } \\
\text { Included) .Fr } 0.30 \text { to } 0.49: \text { normal text Fr } 0.50 \text { or more: underlined text) }\end{array}$} \\
\hline 1 & \multicolumn{2}{|c|}{ Physical } & $\begin{array}{l}\text { Pain, difficulty to sleep or eat. Symptoms of some previous pathology. More in } \\
\text { men or when they come from the countryside. }\end{array}$ \\
\hline \multirow[t]{2}{*}{2} & \multirow[t]{2}{*}{ Emotional } & Women & $\begin{array}{l}\text { Longer initial confusion .Guilty feelings. Self-esteem disorder. Is afraid of } \\
\text { crying to avoid generating more suffering to the patient. Anguish for not being } \\
\text { able to explain the situation to her other children. }\end{array}$ \\
\hline & & Men & Greater expression of anger and difficulty in expressing feelings. \\
\hline 3 & \multicolumn{2}{|c|}{ Behavioral } & $\begin{array}{l}\text { Difficulty verbalizing other medical reports. Competence for care. Biphasic } \\
\text { demand. Exclusion of others members. Differences with their partner. }\end{array}$ \\
\hline 4 & \multicolumn{2}{|c|}{ Spiritual } & $\begin{array}{l}\text { Questioning of beliefs, expression of the desire to fulfill motherhood, search } \\
\text { for meaning. }\end{array}$ \\
\hline 5 & \multicolumn{2}{|c|}{ Social } & Lack of knowledge or misuse of benefits. \\
\hline
\end{tabular}

\section{Description of needs results}

Positive coping resources: To speak of family is to speak of grouping mechanisms of own functioning. [15] It is identifying the 
positive coping resources as: strong family ties, good relationship with other parents in the hospital, giving explanations to what happened through religious beliefs, social networks support, empathic nursing, adequacy of information given by the staff and attention in code of Perinatal Palliative Care.

Negative coping resources: The main negative coping resource observed is: lack of family ties; dysfunctional families; previous unresolved grief; previous psychopathology and refusal of psychological professional help.

German authors emphasize that "The risk of pathological grief variants and chronic grief should be mentioned to parents because professional help is required in such occurrence." (16)

\begin{tabular}{|l|l|l|l|l|}
\hline \multirow{2}{*}{$\mathbf{N} 379$} & \multicolumn{3}{|c|}{$\begin{array}{c}\text { Families Results expressed as relative frequency (Fr = n observed families / N total families Included) .Fr } \\
\mathbf{0 . 3 0} \text { to 0.49: normal text Fr 0.50 or more: underlined text) }\end{array}$} \\
\hline \multirow{2}{*}{6} & $\begin{array}{c}\text { Coping } \\
\text { Resources }\end{array}$ & $6 \mathrm{a}$ & Positive & $\begin{array}{c}\text { Family ties, links with other parents, religion, social networks, empathic } \\
\text { nursing, adequacy of information and attention in the code of PPC }\end{array}$ \\
\cline { 3 - 5 } & $6 \mathrm{~b}$ & Negative & $\begin{array}{l}\text { Lack of family ties; Previous unresolved grief and / or previous psychopathology. } \\
\text { Refuse professional help. }\end{array}$ \\
\hline
\end{tabular}

\section{Model training questionnaire}

"Graduating neonatology fellows are highly trained in the technical skills necessary to care for critically ill and dying neonates but are inadequately trained in the communication skills that families identify as critically important when facing end-of-life decisions." [17]

Training about the parameters of family health in perinatal palliative care is necessary. The authors proposed a model questionnaire to facilitate practioners' approach to families.

1. The needs and resources are listed from one to six and based on the results a questionnaire to identify difficulties has been presented.

2. Each step from one to five identifies a kind of need and step six identifies coping resources: a) positive and b) negative.

3. Step one 1) Do you have pain? Have you eaten today? Have you been able to sleep? Do you take medication? Where are you from? Where are you and your partner staying?

4. Step two 2) what have the doctors explained to you? Do you think that it happens because of a particular reason? What is your greatest concern now? (Enable person to cry). Who is taking care of the other children?

5. Step three 3) Do you need any clarification? What do you worry about when you visit the baby? Have you received any visit? How do you feel treated? Do you feel empowered to take care of your baby? Do you need to explain the situation to a family member? Do you know how the staff works?

6. Step four 4) Do you have a religion? How does your religion regard baptism? Do members of your religion come to visit you?

7. Step five 5) Do you need any explanation about some process? Do you receive social benefits (name them)? Do you need advice about them?

8. Step six 6) coping resources: a) positive: Do you need any explanation about some process? Do you receive social benefits (name them)? Do you need advice about them? And b) negative: Do you want to receive the visit of a psychologist who is a member of the team that takes care of your baby? When would it be convenient to you? Has your phone been updated?

Like other authors we see the need to explore changes in training in these subjects [18]

\begin{tabular}{|c|l|}
\hline $\mathbf{1}$ & $\begin{array}{l}\text { Do you have pain? Have you eaten today? Have you been able to sleep? } \\
\text { Do you take medication? Where are you from? Where are you staying? }\end{array}$ \\
\hline $\mathbf{2}$ & $\begin{array}{l}\text { What have the doctors explained to you? } \\
\text { Do you think that it happens because of a particularly reason? } \\
\text { What is your greatest concern now? (Enable person to cry). } \\
\text { Who is taking care of the other children? }\end{array}$ \\
\hline 3 & $\begin{array}{l}\text { Do you need any clarification? What do you worry about when you visit the baby? } \\
\text { Have you received any visit? How do you feel treated? } \\
\text { Do you feel empowered to take care of your baby? } \\
\text { Do you need to explain the situation to a family member? } \\
\text { Do you know how the staff works? }\end{array}$ \\
$\mathbf{4}$ & $\begin{array}{l}\text { Do you have a religion? } \\
\text { How does your religion regard baptism? } \\
\text { Do they come to visit you? }\end{array}$ \\
\hline
\end{tabular}




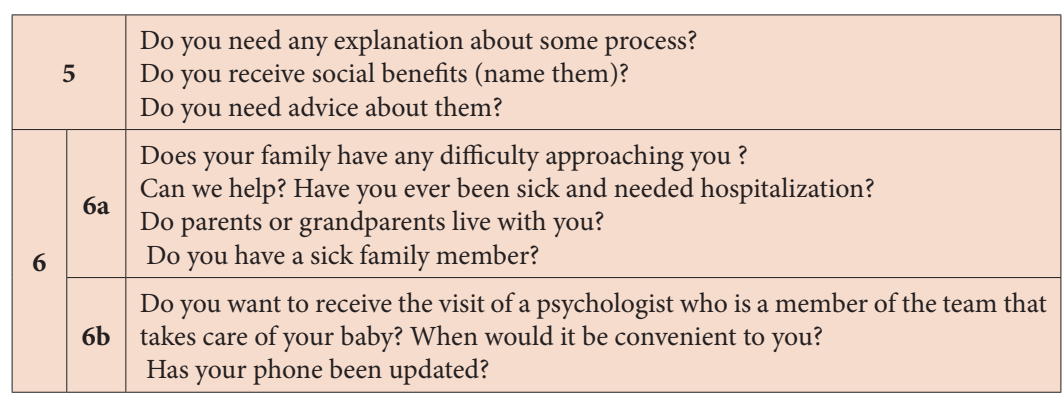

Table 3: Model training questionnaire

\section{Instructive of questionnaire}

At least one workshop must be carried out to learn its use with an instructive. It can be used by health personnel in training in recognition of needs and coping resources. The instructive explain each step and how to use the questionnaire. It is suggested choosing at least two questions of each step and then going deeper in the difficulty which has been found. It should not necessarily be carried out all at once or in that order. The order can be altered if difficulties are suspected in one of the areas. The questions can follow a mobile order according to detected priorities. Table 4 shows both: results and questionnaire to facilitate the management.

\begin{tabular}{|c|c|c|}
\hline N 370 & \multicolumn{2}{|c|}{$\begin{array}{l}\text { Families Results expressed as relative frequency }(\mathrm{Fr}=\mathrm{n} \text { observed families / } \mathrm{N} \text { total families } \\
\text { included).Fr } 0.30 \text { to } 0.49: \text { normal text Fr } 0.50 \text { or more: underlined text) }\end{array}$} \\
\hline 1 & Physical & $\begin{array}{l}\text { Pain, difficulty to sleep or eat. Symptoms of some pathology. More in men or when } \\
\text { they come from rural areas. }\end{array}$ \\
\hline \multirow[t]{2}{*}{2} & \multirow[t]{2}{*}{ Emotional } & $\begin{array}{l}\text { Women: Initial confusion. Guilty feelings. Self-esteem disorder. She is afraid of } \\
\text { crying to avoid generating more suffering to the patient and of not being able to } \\
\text { explain the situation to her other children. }\end{array}$ \\
\hline & & Men: Greater expression of anger and difficulty in expressing feelings. \\
\hline 3 & Behavioral & $\begin{array}{l}\text { Difficulty verbalizing other medical reports. Competence for care. Biph } \\
\text { demand. Exclusion of other members. Differences with their partner. }\end{array}$ \\
\hline 4 & Spiritual & $\begin{array}{l}\text { Retention of beliefs, expression of the desire to fulfill motherhood, search for } \\
\text { meaning. }\end{array}$ \\
\hline 5 & Social & $\begin{array}{l}\text { Lack of knowledge or misuse of benefits. Dissatisfaction, greater in dysfunctional } \\
\text { families. }\end{array}$ \\
\hline \multirow{2}{*}{6} & \multirow{2}{*}{$\begin{array}{l}\text { Coping } \\
\text { Resources }\end{array}$} & $\begin{array}{l}\text { 6a Positive: Family ties, links with other parents, religion, social networks, empathic } \\
\text { nursing, adequacy of information and attention in the code of PPC }\end{array}$ \\
\hline & & $\begin{array}{l}\text { 6b Negative Lack of family ties; Previous unresolved grief and / or previous } \\
\text { psychopathology. Refusal of professional help. }\end{array}$ \\
\hline \multicolumn{3}{|r|}{ MODEL TRAINING QUESTIONNAIRE } \\
\hline 1 & \multicolumn{2}{|c|}{$\begin{array}{l}\text { Have you eaten today? Have you been able to sleep? Do you have pain? Do you take medication? } \\
\text { Where are you from? Where are you staying? Who is taking care of the other children? }\end{array}$} \\
\hline 2 & \multicolumn{2}{|c|}{$\begin{array}{l}\text { What have the doctors explained to you? Do you think that it happens because of a particular } \\
\text { reason? What is your greatest concern now? (Enable person to cry). }\end{array}$} \\
\hline 3 & \multicolumn{2}{|c|}{$\begin{array}{l}\text { Do you need any clarification? Do you need to explain the situation to a family member? What } \\
\text { do you worry about when you visit the baby? Have you received any visit? How do you feel } \\
\text { treated? Do you feel empowered to take care of your baby? Do you know how the staff works? }\end{array}$} \\
\hline 4 & \multicolumn{2}{|c|}{ Do you have a religion? How does your religion regard baptism? Do they come to visit you? } \\
\hline 5 & \multicolumn{2}{|c|}{$\begin{array}{l}\text { Do you need any explanation about some process? Do you receive social benefits (name them)? } \\
\text { Do you need advice about them? }\end{array}$} \\
\hline 6 & \multicolumn{2}{|c|}{$\begin{array}{l}\text { 6a Does your family have any difficulty approaching you? Can we help? Do you have ever been } \\
\text { sick and need hospitalization? Do parents or grandparents live with you? Do you have a sick } \\
\text { family member? }\end{array}$} \\
\hline & \multicolumn{2}{|c|}{$\begin{array}{l}\text { 6b Do you want to receive the visit of a psychologist who is a member of the team that takes care } \\
\text { of your baby? When would it be convenient to you? Has your phone been updated? }\end{array}$} \\
\hline
\end{tabular}

Table 4: Needs and Coping Resources

\section{Conclusions}

Further studies are required in order to generalize the results and the proposed questionnaire will be subject to modifications during validation. However, this study allowed the authors to propose and implement improvements in the care of families such as weekly meetings of parents and relatives in intensive care and meetings with the staff for a greater inclusion of the family in care.

It is useful for coping with the crisis to foster family ties and to bring social programs closer together with integration with other 
families living in the hospital (Weekly meetings).

A questionnaire facilitator for the recognition of these topics is proposed and it could be useful to choose strategies for approaching families in perinatal palliative care.

\section{Acknowledgments}

To the families who taught us so much and the staff who trusted us.

\section{References}

1. World Health Organization (2009) WHO Definition of Palliative Care. Geneva.

2. Rufo R, Ettlin G, Boccarato A, Morales E, Hoppe A, et al. (2013) Perinatal palliative care: three years of maternity experience, XXIX Congress of Pediatrics 2013, Uruguay.

3. World Health Organization (1979) Statistical indexes of the health of the family. Report of an Expert Committee. Geneva 30-3. (Technical Report Series, No. 587).

4. Academic Consensus in Family Medicine of Organisms and Educational Institutions and Health, June 2005.

5. Áres Muzio P. Family psychology: an approach to his study. Havana: Editorial Félix Varela, 2002:

6. Zeidner M, Hammer AL (1992) Coping with missile attack: Resources, strategies, and outcomes. Journal of personality 60: 709-46.

7. Maslow AH (1943) A theory of human motivation. Psychological review 50: 370-96.

8. De la Revilla L, Bailón E, Moreno A, Fleitas L, Alcaine F y Campa F (2001) Un nuevo enfoque de la enseñanza de la atención familiar en el programa de la especialidad de medicina familiar y comunitaria. Medicina de Familia (And) 2: 64-74.

9. Rufo R. (2016) Integration of perinatal palliative care in a maternity: five years of experience, V Uruguayan congress of neonatology, Montevideo.

10. Marc-Aurele KL, English NK (2017) Primary palliative care in neonatal intensive care. Semin Perinatol 41:133-9.

11. Gómez-Batiste X, Espinosa J, Porta-Sales J, Benito E (2010) Modelos de atención, organización y mejora de la calidad para la atención de los enfermos en fase terminal y su familia: aportación de los cuidados paliativos. Medicina clínica 135: 83-9.

12. Power N, Frank L (2008) Parent participation in the care of hospitalized children: a systematic review. J Adv Nurs 62: 622-41.

13. Novellas Aguirre A, Pajuelo Valsera MM (1999) the family of the sick person in SECPAL - medical guides.

14. Youngblut JM, Brooten D (2012) Perinatal and pediatric issues in palliative and end-of-life care from the 2011 Summit on the Science of Compassion. Nurs Outlook 60: 343-50.

15. Boss RD, Hutton N, Donohue PK, Arnold RM (2009) Neonatologist training to guide family decision making for critically ill infants. Arch Pediatr Adolesc Med 163: 783-8.

16. Schulze A, Wermuth I (2007) Compassionate care for terminally ill term and preterm infants. Z Geburtshilfe Neonatol 211: 54-9.

17. Boss RD, Hutton N, Donohue PK, Arnold RM (2009) Neonatologist training to guide family decision making for critically ill infants. Arch Pediatr Adolesc Med 163: 783-8.

18. Salas Arrambide M, Gabaldón Poc O, Mayoral Miravete JL, González Pérez-Yarza E, Amayra Caro I (2004) Pediatric palliative care: a comprehensive model of care for children with life-threatening conditions and their families. Annals of Pediatric 61: 330-5.

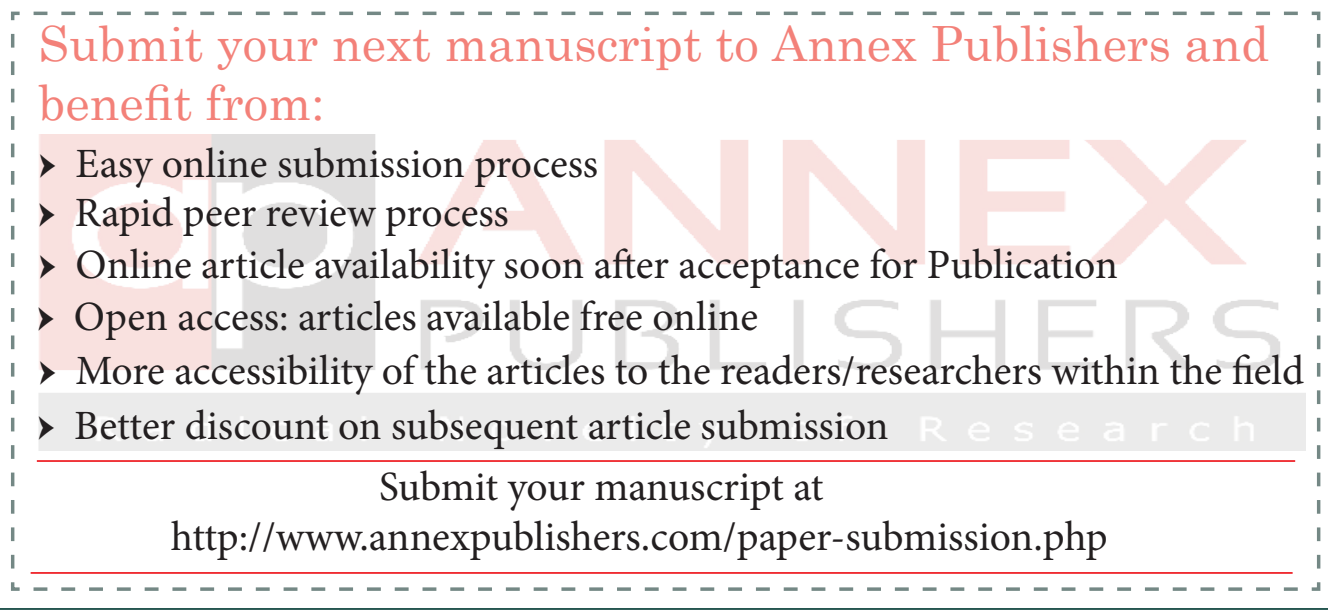

